\begin{tabular}{lc|}
\hline \hline \hline & International Journal of Current Research \\
& and Academic Review \\
EXCELLENT \\
PUBLISHERS
\end{tabular}

doi: https://doi.org/10.20546/ijcrar.2018.605.008

\title{
Review on Factors Affecting Success of Artificial Insemination
}

\author{
Abriham Kebede* \\ School of Veterinary Medicine, College of Medical and Health Science, Wollega University, P.O. Box, 395, Nekemte, \\ Ethiopia \\ *Corresponding author
}

\section{Abstract}

Artificial insemination (AI) is the manual placement of semen in the reproductive tract of the female by a method other than natural mating and it is among the group of technologies commonly known as assisted reproduction technologies (ART), whereby offspring are generated by facilitating the meeting of male and female gametes. It is intended to improve the fertility of low reproductive activity and low production capacity animals in animal reproduction. However, the success of artificial insemination is affected by different factors like: Artificial Insemination delivery system, heat detection and time of insemination, intrinsic factors related to the cow, early embryonic loses, problem of management, semen quality, insemination techniques and people awareness. Therefore, to get the full advantages of artificial insemination, the above factors should corrected as the required standards for using this advantages technology and the management should be taken into consideration and the people should be aware the advantages of artificial insemination.
\end{abstract}

\section{Introduction}

Artificial insemination (AI) is the manual placement of semen in the reproductive tract of the female by a method other than natural mating and it is among the group of technologies commonly known as assisted reproduction technologies (ART), whereby offspring are generated by facilitating the meeting of male and female gametes (Morrell, 2011). The history of AI is interesting in that old Arabian documents dated around 1322 A.D. indicate that an Arab chieftain wanted to mate his prize mare to an outstanding stallion owned by an enemy. He introduced a wand of cotton into the mare's reproductive tract, and then used it to sexually excite the stallion causing him to ejaculate. The semen was introduced into the mare resulting in conception (Webb, 2003).

\section{Article Info}

Accepted: 20 April 2018

Available Online: 20 May 2018

\section{Keywords}

Artificial insemination;

Factors;

Production;

Success.
The first successful AI was performed in Italy in 1780 and over 100 years later, in 1890, it was used for horse breeding (Webb, 2003). In Russia, however, the method was first taken up seriously as a means of improving farm animals (Heinonen, 1989). The author further indicated that Anthony Van Leeuwenhook, inventor of the microscope, first observed human spermatozoa under magnification, which led to further research. In fact, Spallanzani has been recognized as the inventor of AI. His scientific reports of 1780 have indicated successful use of AI in dogs. In 1899, Ivanoff of Russia pioneered AI research in birds, horses, cattle and sheep, and was apparently the first to successfully inseminate cattle artificially (Webb, 2003). Mass breeding of cows via AI was first accomplished in Russia where 19,800 cows were bred in 1931 Webb (2003). 
In Ethiopia, AI was introduced in 1938 in Asmara, the then part of Ethiopia, which was interrupted due to the Second World War and restarted in 1952 (Yemane et al., 1993). It was again discontinued due to unaffordable expenses of importing semen, liquid nitrogen and other related inputs requirement. In 1967 an independent service was started in the then Arsi Region, Chilalo Awraja under the Swedish International Development Agency (Sida). Zewdie et al., (2006) has described that the technology of AI for cattle has been introduced at the farm level in the country over 35 years ago as a tool for genetic improvement. The efficiency of the service in the country, however, has remained at a very low level due to infrastructure, managerial, and financial constraints and also due to poor heat detection, improper timing of insemination and embryonic death.

The use of $\mathrm{AI}$ as a tool to enhance production efficiency in cattle (Holm et al., 2008) and the successful use of artificial insemination (AI) as a means of animal breeding relies upon three major premises: firstly, that spermatozoa can survive outside the body; secondly, that they can be reintroduced into the female genital tract in a way that results in an acceptable conception rate; and thirdly, that the fertile period of the female can be identified (Arthur, 2001; Holm et al., 2008; Manafi, 2011). Artificial insemination offers several potential advantages over natural service, of these, the reason most commonly advocated is as a means of genetic improvement and others include cost effectiveness, disease control, safety breeding, flexibility, and fertility management (Ball and Peters, 2004). The success of artificial insemination in Ethiopia is very in compare to the service given and conception rate of served animal. Therefore, the objective of this review is:-

* To assess factors those affect the success of artificial insemination

* To provide document based information to increase the awareness of Artificial insemination

\section{Factors affecting success of artificial insemination}

The successful outcome of AI in cattle depends on a number of intrinsic and extrinsic factors. Understanding the impact of such factors on the probability of success of AI has primary importance to establish corrective measures (Haugan et al., 2005). Reproductive efficiency is poor in most cattle production systems, mainly cows fail to become pregnant due to various factors related to management, nutrition, reproductive diseases, semen quality and other factors, so that the extension service must ensure that farmers get adequate information on the input required to benefit from crossbreed dairy cows and from those of higher genetic merit (Mekonnen et al., 2010). Factors that affect the success of artificial insemination are:-

\section{The artificial insemination delivery system}

A number of factors have made AI delivery system in Ethiopia inefficient. Among these factors are inefficient management, lack of integration of AI service with livestock health and feed packages, absence of appropriate collaboration among stakeholders, poor motivations and skills of inseminators, lack of readily available inputs such as liquid nitrogen, and absence of proper recording systems (Shiferaw et al., 2003). Some farmers have to move their cows for long distance in search of AI service. This is happening in many areas and the reason is AI technicians are unable to get transport facilities like motor bicycles, fuel, etc. AI is known to be a time dependent activity, in which during this long journey/waiting time, heat period is passed away before the service have been given (Lemma, 2010).

In Ethiopia, there is often complaint of the AI service, by service users for imbalance female and male ratios of calves born in which the latter exceeds in percentage, which is against the interests of most of the beneficiaries (Bekele, 2005). Breeding using AI or natural mating affected male: female calf ratio, which gives sense and can be applicable if the system works. However, the reason why natural mating gave more female progenies than males for cows mating to AI is not clearly known (Bekele, 2005).

\section{Factors related to heat detection and time of insemination}

Knowledge of estrus behavior and the estrus to ovulation interval is essential for estimating the best time to artificially inseminate cattle though this have been not well characterized for zebu breeds (Barros et al., 2006; Reolofs et al., 2010). According to various authors (Arthur, 2001; Morrell, 2011), two phases of the estrous cycle have been documented: follicular and luteal phases. The follicular phase comprises proestrus and estrus, and behavioral estrus and ovulation occur during this phase. In European breeds AI is performed $12 \mathrm{hr}$ after the beginning of estrus to allow for the presence of capacitated spermatozoa in the oviduct at the time of ovulation. In Bos taurus breeds estrus behavior lasts 
approximately $18 \mathrm{hr}$ and ovulation occurs 28 to $31 \mathrm{hrs}$ after the onset of estrus. However in Bos indicus estrus is shorter lasting approximately 10-15 hrs and ovulation occur around $25 \mathrm{hrs}$ after the start of estrus (Pinheiro et al., 1998; Ball and Petters, 2004). Other studies also have been suggested that conception rate will not be reduced substantially if cows are inseminated with in 6hrs after initial observation of estrus (John, 2012). AI conducted at approximately $12 \mathrm{hrs}$ after onset of standing heat potentially has lower fertilization rate with increasing embryo degeneration (Roelofs et al., 2010 and Dalton, 2011).

The duration of standing estrus has been reported by several authors to be shorter in zebu than in taurine cattle. Zebu cows have a shorter $(10.7-11.6 \mathrm{hr})$, less intense estrus which occurs later relative to the estrogen stimulus. As with taurine cattle, the duration of estrus and estrous cycle length tend to be shorter in zebu heifers than in cows (Galina et al., 1996). Zebu cattle have low fertility and this low fertility was reported to be due to poor heat detection, poor signs of estrus, and irregularity of the estrous cycle (Rekwot et al., 1999).

Compared with other factors accuracy of heat (estrus detection) is one of the major factors that determine the efficiency of an AI program. Heat detection in cows is carried out by experienced herdsmen/inseminators who are able to identify those animals with standing heat. Since the period is the shortest period between two successive estrus cycles a meticulous observation is required (Arthur, 2001; Iftikhar et al., 2009). The expression of estrus can be influenced by many factors such as heritability, number of days at postpartum, lactation number, milk production, and health. Environmental factors like nutrition, season, housing, herd size, etc. also play a role in estrus manifestation (Roelofs et al., 2006).

Standing heat can occur any time in a 24 -hour period. However, the most likely time for a cow or heifer to show heat signs is at night but the season of the year can influence this, with more cows showing heat at night in hot weather and more showing heat during the day in cold weather. Hot weather, high production, crowded conditions, and high stress environments may reduce mounting activity. Observers must distinguish among cattle coming in to heat, in standing heat, and going out of heat. Females that are in standing heat, were in standing heat yesterday, or will be in standing heat tomorrow are the most likely herd mates to mount other cows or heifers in heat (Jane et al., 2009) (Table 1).
The optimal time at which insemination should take place relative to ovulation (insemination-ovulation interval (IOI) depends mainly on the fertile lifespan of spermatozoa and on the viable lifespan of the oocyte in the female genital tract (Roelofs et al., 2006). For conception to occur, insemination must take place at the correct stage of the cow's estrus cycle since ova remains viable for about 12-18 hrs after ovulation (RodriguezMartinez, 2000; Cartmill et al., 2001). Successful fertilization highly depends on the time interval from insemination to ovulation meaning that if insemination takes place too early, the sperm is aged and by the time ovulation occurs it cannot fertilize the ovum and if insemination takes place too late, the egg is aged and fertilization and formation of a viable embryo is not likely. Indications exist that, in practice, an enormous variability exists in the timing of insemination relative to ovulation. Successful fertilization highly depends on the time interval from insemination to ovulation meaning that if insemination takes place too early, the sperm is aged and by the time ovulation occurs it cannot fertilize the ovum and if insemination takes place too late, the egg is aged and fertilization and formation of a viable embryo is not likely. Indications exist that, in practice, an enormous variability exists in the timing of insemination relative to ovulation (Roelofs et al., 2005).

There are various reports that indicate low rate of AI service in cattle is mainly due to problems of estrus detection. When natural service is used there are no problems, since a cow will only stand for the bull when she is in estrus, and under free-range conditions a cow may be served several times at each estrus.

Several studies (Arthur, 2001; Jane et al.,2009; Morrell, 2011) report on the correct timing of AI which is a dependent upon true, accurate and early identification of estrus, the accurate identification of the individual animal and informing the inseminator at the correct time.

A cow that is first seen in estrus in the morning is usually inseminated in the afternoon of the same day, whilst a cow that is first seen in estrus in the afternoon is inseminated early the next day (Arthur, 2001). A protocol has been developed using GnRH and PGF2 $\alpha$ that synchronizes the time of ovulation within an $8-\mathrm{h}$ period ( 24 to $32 \mathrm{~h}$ after the second injection of $\mathrm{GnRH}$ ) AI similar to $\mathrm{am} / \mathrm{pm}$ breeding. This precise synchrony of ovulation allows for an effective test to determine the optimal time of AI in relation to ovulation (Roelofs et al., 2006). 


\section{Intrinsic factors related to the cow}

Postpartum problems including endometritis have been reported to have a negative effect on fertility i.e. first service conception rate is poor and primiparous cows have higher conception rates than older cows under use of two timed breeding protocol (Rahim and Asghar, 2007). Reproductive health's of the cow particularly uterine environment is of paramount importance in the success of AI. High reproductive efficiency is dependent on obtaining normal uterine involution, early resumption of ovulation, high efficiency of estrous detection and high conception rates per service (Tenhagena et al., 2001; James, 2006).

The presence of uterine infection prolongs uterine involution and resumption of ovulation. Cows with uterine infection in the early postpartum period generally have lower conception rates at subsequent breeding. Studies confirm that even mild uterine infections adversely affect conception rates (O`Connor, 1993). Rahim and Asghar (2007) described on his finding that health and reproductive disorders to post-calving seriously affect conception rate. Calving and postcalving reproductive disorders seriously affect conception rates. Thus, the key to maximizing conception rates must lie in the prevention of disorders, not treatment after they have occurred. Some evidences indicate cows suffering from metabolic disorders, like milk fever, may have a higher incidence of reproductive disorders and lower conception rates (Arthur, 2001; Rahim and Asghar, 2007).

\section{Early embryonic loses}

Reproductive failure in inseminated cattle results from poor fertilization and embryo survival (Santos et al., 2004). Reduced conception rates could be due to early embryonic mortality which contributes to reproductive inefficiency in lactating dairy cows. Fertility assessed at any point during pregnancy is known to be a function of both conception rate and pregnancy loss (Arthur, 2001; Chebel et al., 2004). Pregnancy loss in lactating dairy cows is greater than that in dairy heifers, though the specific factors responsible for early embryonic loss in dairy cows are not known. Different studies reviewed that early embryonic loss in cattle is difficult to study because no sensitive test similar to that used for women and mares exists (Romano et al., 2007). According to Romano et al., (2007) rate of embryo/fetal death between days 30 and 60 was $14.0 \%$ which may be potential reason for repeat breeding (Singh et al., 2005), and on the other hand the fertilization rate after $\mathrm{AI}$ in beef cows is $90 \%$, whereas embryonic survival rate is $93 \%$ by Day 8 and only $56 \%$ by Day 12 post AI. In dairy cattle, only $48 \%$ of embryos were classified as normal on Day 7 after AI. Thus, substantial pregnancy loss probably occurs within two weeks post AI (Arthur, 2001; Santos et al., 2004).

Rectal palpation at early stage of conception by non practitioner could be also for loss of early pregnancy (Romano et al., 2007). So that the use of transrectal ultrasonography permits an earlier pregnancy diagnosis than palpation per rectum, gives immediate information to confirm pregnancy as well as assess embryo/fetal viability, and reduces the number of false positive diagnoses and false negatives when palpation per rectum is used (Romano et al., 2007). On the other hand conception rate to first service is the combined consequence of fertilization, early embryonic, late embryonic and fetal development, and each of these steps in establishing pregnancy may be affected. Fertilization failure and early embryonic loss, late embryonic/fetal loss, and late abortion represent 20 $45 \%, 8-17.5 \%$ and $1-4 \%$ of pregnancy failure, respectively (Grimard et al., 2006).

\section{Factors related to management}

Several factors related to management play roles in successful pregnancy among which nutritional management contribute the largest proportion. Fluctuation in season which have effect on availability of feed, high environmental temperature and other environmental factors (Haugan et al., 2005) cause stress and the challenge of high disease risk in cross breed cows that contribute to high number of services per conception, late age at first calving and first service, and longer calving interval (Mukasa-Mugerewa, 1989).

Energy status is generally considered to be major nutritional factor that influence reproductive performance Anzar et al., (2003). Also total dietary intake can affect fertility, both at the level of the oocyte and embryo, which means it is important to differentiate between optimum conditions for follicle growth and embryo survival. Nutrition has effect on quality of follicle, oocyte and embryo (Dhaliwal et al., 1996; Funstone et al., 2009). Maurice (2003) briefly described the blastocyst formation as a key developmental process in the growth of an embryo. Dietary intake and diet type can alter the expression of transcripts of genes involved in early embryo development. Nutrient requirements for 
optimum follicle growth and embryo development may be quite different. Hence, the importance of diet around the time of mating and in particular the significance of extreme underfeeds post mating in regulating pregnancy rate becomes evident.

Xu et al., (2010) reported that the peak of embryo death occurs during the first month of pregnancy and controlled feed intake is important to reduce mortality of embryos. The impact of nutrition on embryo survival in ruminants extends beyond the supply of essential nutrients and the modification of the hormones and growth factors that influence embryo development (Robinson et al., 2006).

Housing conditions can also have an effect on the distribution of heat during a 24-hour period. Estrous behavior expression at any housing arrangement that allows cattle to interact throughout the day provides more opportunity for mounting and standing behavior to be expressed which enable to identify estrous cow easily. Especially on cattle housed in tie-stall or stanchion barns must be turned out in order for this behavior to be expressed. O'connor (1993) reported under research conducted on high-producing Holstein cows to what extent slippery footing surface could have affected expression of estrus. The result showed that mounting activity occurs more frequently when cows are on soil rather than concrete. When five estrous cows were individually presented with an opportunity to spend time on soil or on concrete in the presence of a tied cow which was either anestrous cow or a cow not in heat, the test cow spent an average $70 \%$ of the time on ground (O'connor, 1993) and 73\% (Morrell, 2011). The test estrous cow mounted more frequently when a tied estrous cow was on soil rather than on concrete (O‘connor, 1993).

\section{Factors related to semen quality}

Considering the economic investment in semen and other inputs, success must be judged on the basis of pregnancy rate to the first AI. Also, a good first service pregnancy rate response usually signifies good conditions for second service. Additional key factors to be considered as impacting pregnancy rate to first service are semen quality (primarily dependent on choice of bulls). In most breeding strategies, whether estrous synchronization is employed or not, semen quality is one of a critical point to a successful pregnancy. The nature of sub fertility due to the male is proving as complex as that due to the female (Saacke, 2008).

Saacke (2008) emphasized that the importance of semen handling and placement to achieve threshold or above threshold number of sperms to the ovum necessary to maximize both 14 fertilization rate and embryo quality. Spermatozoa become very sensitive to any form of stress in their environment in vivo as well as in vitro. As a result, fertility from frozen thawed semen is poorer than that obtained from fresh semen (Lemma, 2011; Arthur, 2001). For this reason, proper evaluation of the post thaw quality of spermatozoa is of utmost interest for AI industry to obtain information on the fertilizing capacity of the cryopreserved semen. Many tests of sperm motility, morphology, acrosomal status, defective sperm organelles and DNA, and metabolism have been correlated with fertility (Lemma, 2011).

Table.1 Timing of estrus detection in cattle timeline for heat signs in cattle (Ball and Petters, 2004)

\begin{tabular}{|c|c|c|c|}
\hline Coming into Heat & Standing Heat & & Going out of Heat \\
\hline \multirow[b]{2}{*}{ Heat Signs } & (6 hours) & (12 hours) & (14+ hours) \\
\hline & $\begin{array}{l}\text {-Stands bellows and } \\
\text { Smells other cows } \\
\text {-Head butts other cows } \\
\text {-Attempts to ride other } \\
\text { cows but will not stand } \\
\text { to be mounted } \\
\text {-Red, moist, slightly } \\
\text { swollen vulva } \\
\text {-Clear mucous discharge } \\
\text { from vulva }\end{array}$ & $\begin{array}{l}\text {-Stands to be } \\
\text { mounted } \\
\text {-Rides other cows } \\
\text {-Bellows } \\
\text { frequently } \\
\text { Nervous } \\
\text { excitable }\end{array}$ & $\begin{array}{l}\text {-Attempts to ride other } \\
\text { cows but will not stand to } \\
\text { be mounted } \\
\text {-Smells other cows } \\
\text {-Clear mucous discharge } \\
\text { from vulva }\end{array}$ \\
\hline
\end{tabular}




\section{Factors related to insemination techniques}

One of the most significant contributions to the successful application of AI in cattle breeding has been made by the highly trained inseminator (Arthur, 2001). The efficiency of cow insemination depends, among other factors, on the ability of the inseminator to deliver the semen to the appropriate site in the reproductive tract at the appropriate stage of estrus. However, there has been a tendency to adopt routine insemination techniques and to ignore inseminator-related factors that can dramatically affect fertility. Although professional inseminators palpate the reproductive tract of numerous cows every day, most are not trained to examine the uterus and ovaries. This poses a serious practical limitation to the success of AI (López-Gatius, 2011). Animals showing signs of true heat should inseminate using frozen semen thawed at $370 \mathrm{C}$ for 30 seconds (Iftikhar et al., 2009).

Professional technicians are more successful at insemination than inexperienced ones, indicating that selection of a qualified inseminator to be an important element in the success of AI program and regular practice at inseminating is required to maintain high conception rates. The site of semen deposition has been an important factor in the success of AI in cattle (Gebremedhin 2008). The deposition of semen in the uterine body resulted in a $10 \%$ higher non-return rate than did cervical deposition and an increase in the conception rate has been reported when semen was deposited in the uterine horns rather than the uterine body. Cows are inseminated just into the short uterine body (O`connor, 2003).

Insemination into the cervix produces a lower fertilization rate, while insemination deeper into the uterus runs the risks of either inseminating into the uterine horn contra lateral to the ovulation site, or scaring the endometrium with the tip of the insemination catheter. Reduced fertility is the consequence of both of the latter two errors (Arthur, 2001). In the early days of AI there was controversy among researchers about the proper site for semen deposition. Fertility was highest when semen was deposited in the uterine body. Researchers currently are re-examining insemination technique to determine the proper site of semen deposition. Failure to understand the anatomical and functional relationships among the various tissues and organs of the reproductive system may lead to consistent insemination errors (Arthur, 2001; O'connor, 2003).
The ability to perform an intrauterine insemination in cattle means that a relatively low dose of sperm is required to achieve acceptable pregnancy rates. Typically, of the 20-30 million sperm that are required in each insemination dose, 6-7 million survive freezing, that is generally regarded as the minimum dose compatible with acceptable fertility (Arthur, 2001). However, site of insemination was found to make only small increases in sperm per egg. Very deep insemination can enhance sperm delivery. Deep insemination should be used only when the sperm dose is below threshold, or if sexed semen is being used. Also hygiene, thawing methods, temperature maintenance between thawing to insemination do play a factor in achieving pregnancy. Rectal palpation and ultrasound examinations should be considered safe procedures when performed correctly, and recent evidence gives no indication that ultrasound examination is detrimental to the embryos (Morrell, 2011).

\section{People awareness}

Although the AI practice has been accepted by fairly a good proportion of livestock owners, certain factors greatly influence acceptance of this practice by others. These factors are infrastructural facilities, farmer's awareness about AI and its merits, lack of farmer's interest, lack of communication and also lack of incentives to farmers and persons engaged in AI work at rural centers. Attempts to improve the efficiency of AI should be based up on the understanding of most important causes for failure. In most of the cases the constraints of using AI service were described to have resulted from lack of awareness, having own bull, lack of infrastructure and low conception rate (Ashebir et al., 2016).

Success rate of AI technology in breeding, its accessibility, and the ability of the AI calf surviving in pastoral areas were key factors that influenced low preference for the AI. Moreover, pastoralists' level of preference for AI was significant and positively influenced by education levels, herd size, household size, and group membership, access to extension services, production system, location and awareness of the technology. However, livestock keeping experience and the age of the pastoralist had negative significant effects. Significant institutional variables such as; access to extension services and group membership provide important policy intervention avenues when designing strategies to enhance adoption of $\mathrm{AI}$ in pastoral areas by 
the government and non-governmental organizations (Khainga et al., 2015).

\section{Conclusion and Recommendations}

Artificial insemination (AI) is the manual placement of semen in the reproductive tract of the female whereby offspring are generated by facilitating the meeting of male and female gametes. It is intended to improve the fertility of low reproductive activity and low production capacity animals in animal reproduction. However, the success of artificial insemination is affected by different factors like: Artificial Insemination delivery system, heat detection and time of insemination, intrinsic factors related to the cow, early embryonic loses, problem of management, semen quality, insemination techniques and people awareness. Therefore, based on the above conclusion the following recommendations were forwarded to get the full advantages of artificial insemination:

$>$ The above factors should corrected as the required standards for using this advantages technology

$>$ The management practice should be taken into consideration and improved as it can be one factor for the success of Artificial insemination.

$>$ The people should be aware the advantages of artificial insemination.

\section{Lists of abbreviation and acronomy}

$\begin{array}{ll}\text { AI } & \text { Artificial insemination } \\ \text { ART } & \text { Assisted Reproduction } \\ \text { Technologies } & \\ \text { DNA } & \\ \text { hr or hrs } & \begin{array}{l}\text { Deoxyribonucleic Acid } \\ \text { hour or hours } \\ \text { IOI } \\ \text { Interval } \\ \text { GnRH } \\ \text { Hormone } \\ \text { PGF2 } \alpha\end{array} \\ \end{array}$

\section{Acknowledgements}

I like to express my gratitude to Wollega University, College of Medical and health science, School of Veterinary Medicine and the Staff of School of Veterinary Medicine for inspiration and comprehensive moral support

\section{References}

Anzar M, Farooq U, Mirza MA, Shahab M and Ahmad N (2003): Factors Affecting the Efficiency of Artificial Insemination in Cattle and Buffalo in Punjab. Pakistan Veterinary Journal, 23:106-113.

Arthur GH (2001): Arthur's Veterinary Reproduction and Obstetrics. Eighth edition, Pp: 430- 767.

Ashebir G, Birhanu A, Gugsa T (2016) Status of Artificial Insemination in Tigray Regional State, "Constraints and Acceptability under Field Condition". J Dairy Vet Anim Res 3(3): 00078. DOI: $10.15406 / j d v a r .2016 .03 .00078$

Ball PJH and Peters AR (2004): Reproduction in Cattle. Third edition, Fibiol. Pp:1-13.

Barros CM, Pegorer MF, Vasconcelos JLM, Bruno GE and Fabio MM (2006): Importance of sperm genotype (Indicus versus Taurus) for fertility and embryonic development at elevated temperatures. Theriogenology, 65: 210-218.

Bekele $T$ (2005): Calf Sex Ratios in Artificially Inseminated and Natural Mated Female Crossbred Dairy Herd. In: proceedings of the 13th annual conference of the Ethiopian Society of Animal Production. Addis Ababa, Ethiopia, Pp: 225-230.

Cartimill JA, El- Zarkouny SZ, Hensley B, Lamb GC and Stevenson JS (2001): Stage of cycle, incidence and timing of ovulation and pregnancy rates in dairy cattle after three timed breeding protocols. Journal of Dairy Science, 84:1051-1059.

Chaundhari SUR and Sabo YG (2006): Techniques for Reproductive Effciency with reference to oestrus detection and Timing of Insemination in Cattle. Journal of Applied Science, 6(10): 2141-2150.

Chebel RC, Santos JEP, Reynolds JP, Cerri RLA, Juchem SO and Overton M (2004): Factors affecting conception rate after artificial insemination and pregnancy loss in lactating dairy cows. Animal Reproduction Science, 84: 239-255.

Dalton JC (2011): Strategies for Success in Heat Detection and artificial Insemination. Advances in Dairy Technology, 23:215-229.

Dekeba A, Ayalew W, Hedge PB, and Taddese Z (2006): Performance of the Abernossa Ranch in the production of Ethiopian Boran x Holstein crossbred dairy heifers in Ethiopia. In: Ethiopian Journal of Animal production 6: 33-53.

Dhaliwal GS, Murray RD and Dobson H (1996): Effects of Milk Yield and Calving to First Service interval, in Determining herd Fertility in Dairy Cows. Animal Reproduction Science, 41: 109- 117.

Funston RN, Larson DM and Vonnahme kA (2009): 
Implications for beef cattle production effects of maternal nutrition on conceptus growth and offspring performance: Journal of Animal Science, 88: 205-215.

Galina CS, Orihuela A and Rubio I (1996): Behavioural Trends Affecting Oestrus Detection in Zebu Cattle.
Animal Reproduction Science, 42: 465-470.

GebreMedhin D (2005): All in one: A Practical Guide To Dairy Farming. Agri-Service Ethiopia Printing Unit, Addis Ababa. Pp: 15-21.

\section{How to cite this article:}

Abriham Kebede. 2018. Review on Factors Affecting Success of Artificial Insemination. Int.J.Curr.Res.Aca.Rev. 6(5), 42-49. doi: https://doi.org/10.20546/ijcrar.2018.605.008 